\title{
Gayrimenkul değerlemesinde geleneksel yöntemler
}

\author{
Traditional methods in real estate valuation
}

\author{
Kemal ÇELIK ${ }^{* 1, a}$ \\ ${ }^{1}$ Gümüşhane Üniversitesi, Mühendislik ve Doğa Bilimleri Fakültesi, Harita Mühendisliği Bölümü, 29100, Gümüşhane
}

\begin{tabular}{lll}
\hline - Geliş tarihi / Received: 22.04.2021 $\quad$ •Düzeltilerek geliş tarihi / Received in revised form: 28.11.2021 $\quad$ Kabul tarihi / Accepted: 12.12 .2021 \\
\hline
\end{tabular}

\begin{abstract}
$\ddot{O} z$
Gayrimenkul değerlemesi, gayrimenkul veya ilişik hakların belirlenen zaman periyodunda muhtemel değerinin gerçeğe yakın olarak belirlenmesidir. Gayrimenkul piyasasının güvenli işleyebilmesi, gayrimenkullerin güncel ve gelecekteki rayiç değerlerinin bilinmesine bağlıdır. Gayrimenkullerin gerçek değerlerinin bilinmemesi, alım-satım işlemleri, emlak vergisi, kentsel dönüşüm uygulamaları vb. işlemlerde sorun oluşturmaktadır. Gayrimenkullerden güncel değere göre vergi alınmaması ekonomik kayıplara neden olmaktadır. Günümüzde nominal değerleme, çoklu regresyon ve yapay sinir ağları, bulut CBS vb. farklı birçok kitlesel değerleme yöntemleri taşınmaz değerleme işlemlerinde kullanılmaktadır. Ülkemizde geleneksel tekil değerleme yöntemi olarak kullanılmakta olan maliyet yöntemi, gelir yöntemi ve emsal karşılaştırma yöntemleri bu çalışmada örnek değerleme çalışması eşliğinde tartışılmıştır. Yapılan bu örnek değerleme çalışmasında arazi, arsa tanımları üzerinde durularak, esasen konut alanı ve sanayi alanına isabet eden alanlarda karşılaştırma yöntemi kullanılarak değerleme yapılmıştır. Samsun İli, Atakum İlçesi, Büyükkolpınar Mahallesi ve Gümüşhane İli, Merkez, Bağlarbaşı Mahallesi sırasıyla konut ve sanayi alanı değerlemesi çalışması için pilot bölge seçilmiş ve buna uygun olarak parsel alanı, imar hakkı, satış tarihi, satış değeri verileri elde edilmiştir. Kentteki konut alanına isabet eden arsalar ile sanayi alanı tanımlı arsaların değerlerinin değerleme birimleri (alan/hacim) açısından farklı olduğu tartışılmıştır.
\end{abstract}

Anahtar kelimeler: Arsa, Değer, Değerleme, Değerleme yöntemleri, Gayrimenkul

\begin{abstract}
Real estate valuation is the determination of the possible value of the real estate or attached rights as close to the truth in the determined time period. The safe operation of the real estate market depends on knowing the current and future market values of real estates. Not knowing the real values of real estates causes problems in such market actions as buying and selling transactions, real estate tax, urban transformation applications, etc. Failure to collect taxes in accordance with the currrent real value causes economic losses. Currently, a variety of mass valuation methods such as naminal valuation, multiple regression, artificial neural networks, cloud GIS etc. are used in the process of real estate valuation. Cost, income and peer comparison methods which are used as conventional single valuation methods in Turkey are discussed in this study in accordance with sample valuation study. In this sample valuation study, after clarifying rural and urban land, valuation study for residential and industrial urban land are carried out by basically using the comparison approach. Büyükkolpınar district in Atakum county of Samsun province and Bağlarbaşı district in central county of Gümüşhane province are selected as the pilot areas for residential and industrial land valuation studies respectively, and plot area, zoning rights, transaction time and value information are collected accordingly. That the value of land corresponding residential and industrial areas is different in accordance with the valuation units (square meters; cubic meters) are discussed.
\end{abstract}

Keywords: Land, Value, Valuation, Valuation methods, Real estate

\footnotetext{
${ }^{* a}$ Kemal ÇELIK; gumuscelik@hotmail.com, Tel: (0456) 23310 00, orcid.org/ 0000-0003-0662-5901
} 


\section{Giriş \\ 1. Introduction}

Gayrimenkul değerleme, gayrimenkul veya taşınmazda geliştirilen projenin, ilişkili faydaların istenilen zamandaki değerinin objektif kriterlere ve nitelik, fayda, çevre, işlevsellik gibi verilere dayanarak belirlenmesidir. Taşınmazın bugünkü değeri kullanılarak geçmiş zamandaki değerinin hesaplanmas1 yapılabilmektedir. Değerleme işlemleri; mülkiyetin devri, finansman ve kredi işlemleri, kamulaştırma işlemleri, vergilendirme, kiralama, kentsel yenileme ve fizibilite çalışmalarında, sigortalama işlemleri, kentsel dönüşümlerde arsa ve binaların değerlerinin tespiti ve arsa ve arazi düzenlemeleri konularında gerçekleştirilir (Öztürk, 2017). Değer sözcüğü dilimizde pek çok anlamda kullanılmaktadır. Değer, kamulaştırma, arazi ve arsa düzenlemeleri, arazi toplulaştırması, yatırım, piyasa, sürüm, pazar, satış, vergilendirme, gelir vergisi, sigorta, kredi, miras, ipotek, maliyet, tavan, veraset vb. işlemlerinde gayrimenkullerin değerinin bilinmesine ihtiyaç duyulmaktadır (Çelik \& Aşık, 2004) Değerleme, vergi matrahlarının hesaplanmasında ilgili iktisadi kıymetlerin takdir ve tespiti işlemlerinde kullanılmaktadır (Vergi Usul Kanunu, 1961, 258).

Taşınmazın değeri, "istekli satıcı ve istekli alıcı arasında, tarafların herhangi bir ilişsiden etkilenmeyeceği şartlar altında, hiçbir zorlama olmadan, basiretli ve konu hakkinda yeterli bilgi sahibi kişiler olarak, uygun bir pazarlama sonrasinda değerleme tarihinde gerçekleştirecekleri alım satım işleminde el değiştirmesi gerektiği takdir edilen tutardır" (Açlar \& Çağdaş, 2008)

Gayrimenkul değerlemesi ile ilgili standart ve tanımlamalar; RICS, TEGoVA ve IVSC gibi değerleme kurumları tarafindan geliştirilmektedir. RICS (Royal Institution of Chartered Surveyors: Yeminli Uzmanlar Kraliyet Enstitüsü) Londra merkezli olup, gayrimenkul değerleme ve aracılık hizmetlerine kapsamlı hizmet sunmaktadır (RICS, t.y.). RICS gayrimenkul değerlemesi yanında taşınabilir kıymetlerin değerlemesi hizmeti vermektedir. TEGoVA (The European Group of Valuers' Associations: Avrupa Değerleme Örgütleri Birliği), Avrupa'da Brüksel merkezli taşınmaz değerlemesi çatı örgütüdür (TEGOVA, t.y.). IVSC (The International Valuation Standards Council: Uluslararas1 Değerleme Standartları Konseyi), Londra merkezli olup, yatırımcıların ve diğerlerinin dayandığı değerlemeler için uluslararası teknik ve etik standartlar geliştirir (IVSC, t.y.).

Değerleme yaklaşımı terimi yaygın bir şekilde kullanılan genel kabul görmüş analitik yöntemleri ifade eder.

Uluslararas1 Değerleme Standartları Eki Uluslararası Değerleme Standartlarının Değerleme yaklaşımları başlıklı 2.9. maddesinde, pazar değerinin belirlenmesi için karşılaştırılabilir işlemler yöntemi, borsadaki kılavuz emsaller yöntemi sistematik olmayan veya "pratik yöntem" olarak bilinen değerleme kıstasları pazar yaklaşımı olarak kullanılmaktadır. Yapılacak değerlemede birden fazla değerleme yöntemi kullanılması tavsiye edilmektedir (Uluslararası Değerleme Standartlar1, 2017).

$\mathrm{Bu}$ çalışmanın asıl konusu olan karşılaştırma yöntemi olduğu için karşılaştırma yöntemini ele alan çalışmaların araştırılması yapılmıştır. Gayrimenkul değerlemesinde geleneksel yöntemlerden karşılaştırma tekniğinin yaygın ve dünyada genelinde kabul görmüş bir teknik olduğunu, teorik olarak tüm dünyada aynı olmasına rağmen bu yöntemin yerelde uygulanmasında farkl11ıklar olduğunu belirtmiştir (Munshifwa, 2021). Zambia'da bu yöntemin az bilinen indirgenmiş kat alanı (reduced floor area) yöntemi olarak uygulandığ ağırlıklandırılması esasına dayandığı, değerleme uzmanlarının ülkede yaygın olarak bu yöntemi kullandığı, yöntemin kurallarının kulaktan kulağa yeni nesil değerlemecilere aktarıldığı, bu nedenle uygulamada farklılıklar olabildiğini vurgulamıştır. Çalışma sonucu olarak ise bu yöntemin savunulabileceğini ancak kullanılan bazı sabit ağırlı faktörlerinin profesyonel değerleme uzmanlarını da işin içine dahil edilerek tartışılması ve böylece değerlemelerdeki farklılıkların azaltılması için çalışılması gerektiğini vurgulamıştır. Lisi, (2019) tarafindan karşılaştırma ve çoklu regresyon analizi yöntemlerini kullanarak taşınmaz değerlemesinde bağımsız değişkenler olarak kullanılan yapı karakteristiklerinin etkisi tartışılmıştır. Öncelikle karşılaştırma ve çoklu regresyon yöntemleri arasındaki yakın ilişkiyi teyit etmektedir. Çalışmada kestirim fiyatların konut değerlemesindeki önemli rolü kanıtlanmıştır. Karşılaştırma yönteminde faktörlerin dengelenmesinde (ağıllıklarının belirlenmesinde) önerilen iki yöntemin çoklu regresyon ve eşleştirilmiş (paired) veri analizi olduğunu, ancak bu yöntemlerin tüm değerleme uygulamalarında kullanılamadığını, heterojen yapılaşma ve az miktarda satışı olduğu durumlarda kullanılamadığını ileri sürmüştür (Lisi \& Iacobini, 
2018). Karşılaştırma yönteminde hiçbir belirsizliği olmadığ 1 durumlarda bile hem değerleme uzmanları ve hem de müşterilerin istatistiki yöntemleri kullanmaktan kaçındıklarını, ayrıca değerleme uzmanlarının belirsizlik olmayan durumlarda kullandıkları yöntem gereği kendilerine ve yeteneklerine güvenlerinin tam olduğunu ancak belirsizlik durumunda basit kurallı modelleri kullanmak yerine modellenmesinin imkânsız olduğunu düşündükleri kendilerine has yöntemlere başvurmakta olduklarını ileri sürmüştür. Karşılaştırma yöntemini mantıklı kurallara bağlayarak daha güvenilir bir araç haline getirip, konut, işyeri ve hatta makine/teçhizat satış ve kiralama işlemlerinde, bazı belirsizlik durumlarının da olduğu durumlarda güvenilir bir araç olarak kullanılabileceğini ortaya koymuştur (Van \& David, 2017). ABD North Carolina eyaletinde 2500 civarında apartman dairesi satış verileri kullanilarak hedonik fiyat fonksiyonunu yar1-parametrik regresyon ile birlikte kullanılmış ve geleneksel parametrik modellerle karşılaştırılmıştır. Yöntemin veri olan ve olmayan bölgelerde değerleme işlemlerinde kullanılabileceği sonucuna varılmıştır (Bin, 2004). Hans, (2002)'de yaptığı çalışmada değerleme uzmanlarının ve akademisyenlerin karşılaştırma yöntemi ile yapılan değerlemeye bakış açılarının farklılığını ortaya koymuştur. Farklılıkların ortaya koyulmasında lineer formüller kullanmaktadır. Değerleme uzmanlarının çok az emsal değer verisi kullanarak uzman görüşü ile değerleme yaptıklarını ve birçok değerin olabileceği öngörüsü ile hareket ettiklerini vurgulamaktadır (Hans, 2002). Akademisyenlerin ise tek değer prensibi üzerine daha çok emsal veri ve birçok istatistik yöntemi kullanarak çözüm aradıklarını vurgulamaktadır. Karşılaştırma yöntemi dünya çapında yaygınca kullanılan istatistiki modeller olan dengelemeli karşılaştırma, hedonik regresyon ve hedonik fiyat indeksi modelleri kullanılarak, değerleme işlemlerinin etkinliğini artırmak için çoğul-amaçlı optimizasyon ve çok kriterli karar analizi yöntemlerinin bir kombinasyonu olarak değerleme modeli geliştirilmiştir (Farkas \& Porumb, 2020). Cupal, (2016) tarafindan yapılan çalışmada, 140 emsal değer ve farklı türlerde 849 adet taşınmaz bulunan bir veri seti üzerinde değeri etkileyen 11 adet bağımsız değişken kullanmak suretiyle konut değerlemesinde Lineer Regresyon Modeli ile bulunan değeri etkileyen faktörleri ve emsal karşılaştırmada kullanılan değer dengeleme faktörlerinin karşılaştırmasını yapmış ve kısmen aralarındaki benzerliği ortaya koymuştur. 140 değerleme verisi ve 500 adet gerçek satış fiyatı verilerini kullanarak veri heterojenliğinin yapılan değerlemenin doğruluğuna etkisini istatistiki yöntemler kullanarak araştırmıştır (Cupal, 2017). Karşılaştırma yöntemi ile yapılan değerleme işlemlerinde birim seçimini ele almaktadır (Donald \& Jess, 1996). Tartıştı̆̆ konulardan birisi de az bir veri seti ile değerleme yapmak gerektiğinde farklı değerleme birimlerinin güvenirlik derecesinin belirlenebileceği şeklindedir. Regresyon modelinde anlamlı değişkenler ve bunların ağırlıklarının belirlenmesi için 6345 emsal değerleme verisi üzerinde çoklu regresyon yöntemi uygulanmıştır. Verilerin \%90'i test için kalan $\% 10$ 'u ise doğrulama için kullanılmış ve alternatif yöntemler önerilmiştir (Ming You \& Chang, 2009).

Ülkemizde, gayrimenkul değerlemesinde genellikle geleneksel yöntemler kullanılmasına karşın karşılaştırma yönteminde elde edilmiş olan verilerin nasıl kullanılacağı konusunda karmaşa bulunmaktadır. Yaptığımız çalışma ile konut ve sanayi alanındaki emsal verilerden yararlanılarak karşılaşma yöntemine göre değer belirlemesi basit örneklerle gösterilmiştir. Değerleme kavramının anlaşılabilmesi için arazi ve arsa kavramının açıklanması gerekmektedir.

\subsection{Arsa ve arazi nedir?}

\subsection{What is urban plot and rural land?}

Arazi, insanların temel faaliyet alanıdır. Dolayısıyla insanoğlunun yaşamı boyunca araziyle ilişkisi hep olmuştur. (Yomralıoğlu, vd., 2011; Yıldız, 2000) tarafından arazi için yapılan tanım ise "yeryüzü parçast, yer, toprak, ekilip biçilen topraklar; insanların oturduğu ya da boş toprak parçasıdır" şeklindedir. Arsa, 1/1000 ölçekli uygulama imar planı ve imar mevzuatına göre oluşmuş imar parselidir (Arazi ve Arsa Düzenlemeleri Hakkında Yönetmelik, (2020). (Deveci \& Yilmaz, 2009) tarafindan yapilan tanımlama "Imar Kanunu uyarınca arazi ve arsa düzenlemesi görmüş en az altyapısı sağlanmış imar parselidir" şeklindedir.

Parselasyonu yapılmış, imar mevzuatına göre yapılaşma yapilabilen ve yerleşilebilen alanlara arsa denilmektedir. Geleneksel olarak imarsiz ve imarlı arsa olarak isimlendirilir (Taygır \& Hacıköylü, 2018). 1319 Sayılı Emlak Vergisi Kanunu'na göre her arazinin bir arsa olmayacağ 1 fakat her arsanın bir arazi olduğu kabul edilmiştir. Belediye sınırları içine isabet eden, belediye hizmetlerinden yararlanan parselasyonu yapılmış araziler "arsa" sayılmaktadır. Belediye mülki sınırları dışında veya içindeki parselasyonu yapılmamış taşınmazların hangilerinin arsa sayılacağı 1319 Sayılı Emlak Vergisi Kanunun (1970) 12. Maddesine göre Bakanlar Kurulu kararı 
ile belli edilir. Kanunu'nun 12. maddesine göre, belediye sınırları dışında veya içinde bulunan parsellenmemiş araziler de arsa kavramı içerisinde değerlendirilmektedir. $\mathrm{Bu}$ kapsamda belediye sınırlarına dâhil olan veya İl Özel İdaresi sorumluluk sahasındaki parsellenmemiş arazilerden hangilerinin arsa sayılacağ 1983/6122 numaralı Bakanlar Kurulu Kararı ile belirlenmektedir. Bakanlar Kurulu arasa ve arazi ayırımını 11.03.1983 tarih ve 17984 say1l Resmi Gazete'de yayınlanan 1983/6122 numaralı kararı ile belirlemiştir.

Vergi hukuku açısından arazi, arz üzerinde sınırları, çit, yol, dağ, duvar, ağaç vb. gibi sun'i ve tabii eşiklerle çevrili yeryüzü parçası olarak tarif edilmektedir. Arazideki kaynaklar, göl ve ağaçlar arazinin mütemmim cüzü sayılmaktadır. Benzer tanım arsalar için de yapılabilmektedir. Ancak, Emlâk Vergisi Kanunu göre arsa ve arazi birbirinden farklı beyanname düzenlemektedir. Arsa ve arazinin vergi oranlarının farklı olması nedeniyle ayrı tanımalar yapılmaktadır. Arsa parsellenmiş arazi parçalarını ifade etmektedir. $\mathrm{Bu}$ bakımdan, belediye sınırları içinde, parselasyonu yapılmış arazi parçaları ile köy sınırlarında olan belediye mücavirindeki alanların tamamı arsa olarak değerlendirilmektedir.

Arazi tanımı 5403 sayılı Toprak Koruma ve Arazi Kullanımı Kanununun 3. Maddesinde yeniden tanımlanarak "Toprak, iklim, topografya, ana materyal, hidroloji ve canlıların değişik oranda etkisi altında bulunan yeryüzü parçasını ifade eder" şeklinde tanımlanmıştır.

Arazilerin "arsa" olabilmesi için öncelikle 1/100000 ölçekli Çevre Düzeni Planında konut tanımlı alana karşılık gelmesi gerekmektedir. $\mathrm{Bu}$ alanların 1/5000 Nazım İmar Planlanın da yapılmış olması gerekmektedir. Nazım imar planı, "mevcut ise çevre düzeni planinın genel ilke, hedef ve kararlarına uygun olarak, arazi parçalarının genel kullanış biçimlerini, başlıca bölge tiplerini, bölgelerin gelecekteki nüfus yoğunluklarını, çeşitli kentsel ve kursal yerleşme alanlarınin gelişme yön ve büyüklükleri ile ilkelerini, kentsel, sosyal ve teknik altyapı alanlarını, ulaşım sistemlerini göstermek ve uygulama imar planlarinin hazırlanmasina esas olmak üzere, varsa kadastral durumu işlenmiş olarak 1/5.000 ölçekte, büyükşehir belediyelerinde 1/5000 ile 1/25.000 arasindaki her ölçekte, onaylı halihazır haritalar üzerine, plan notlarl ve ayrintıl raporuyla bir bütün olarak hazırlanan planı" ifade eder (Mekânsal Planlar Yapım Yönetmeliği, 2014, 5). Nazım imar planında yapılaşmaya uygun konut alanı ile yapılaşmaya yasak alanlar görülebilmektedir. 1/1000 ölçekli Uygulama İmar Planında parselasyon yapılması halinde konut alanına isabet eden araziler "Arsa" statüsüne kavuşmaktadır. Araziden arsaya dönüşümde en fazla \%45 oranında DOP (Düzenleme Ortaklık Pay1) kesilebilmektedir (İmar Kanunu, 1985). Ham arazinin imara konu edilmesi ve imar uygulama yöntemleri aracılığı ile arsa oluşumu sağlanmaktadır.

\section{Materyal ve metot \\ 2. Material and method}

\section{1. Çalışma alanı}

2.1. Study area

Konut arsası için değerleme bölgesi Samsun İli, Atakum İlçesi, Büyükkolpınar Mahallesi ve Sanayi alanı (Şekil 1) için ise Gümüşhane İli, Merkez, Bağlarbaşı Mahallesinde sanayi alanı (Şekil 2) seçilmiştir. Konut arsasında karşılaştırma yapabilmek için ada/parsel, parsel alanı, imar hakkı (emsal), satış tarihi, satış değeri verileri toplanmıştır. Sanayi arsasında karşılaştırma yapabilmek için ada/parsel, parsel alanı, yükseklik, imar hakkı(emsal), satış tarihi, satış değeri verileri toplanmıştır. 


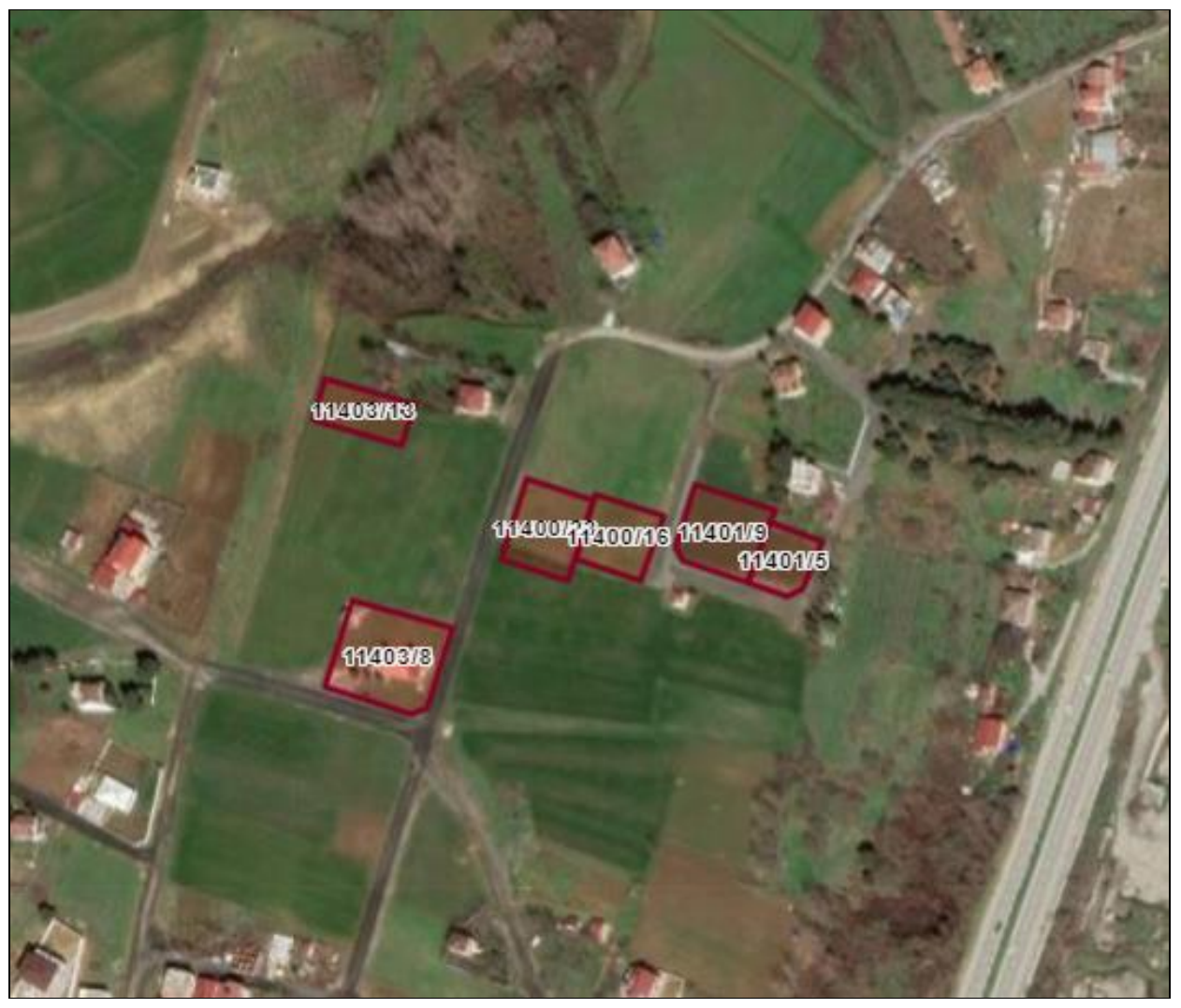

Şekil 1. Konut arsası değerlemesi yapılan Samsun İli, Atakum İlçesi, Büyükkolpınar Mahallesi konut alanında emsal alınan parsellerin Google Earth görüntüsü

Figure 1. Google Earth image of peer land parcels for residential area of Samsun Province, Atakum County, Buyukpinar District where residential land parcel valuation is conducted.

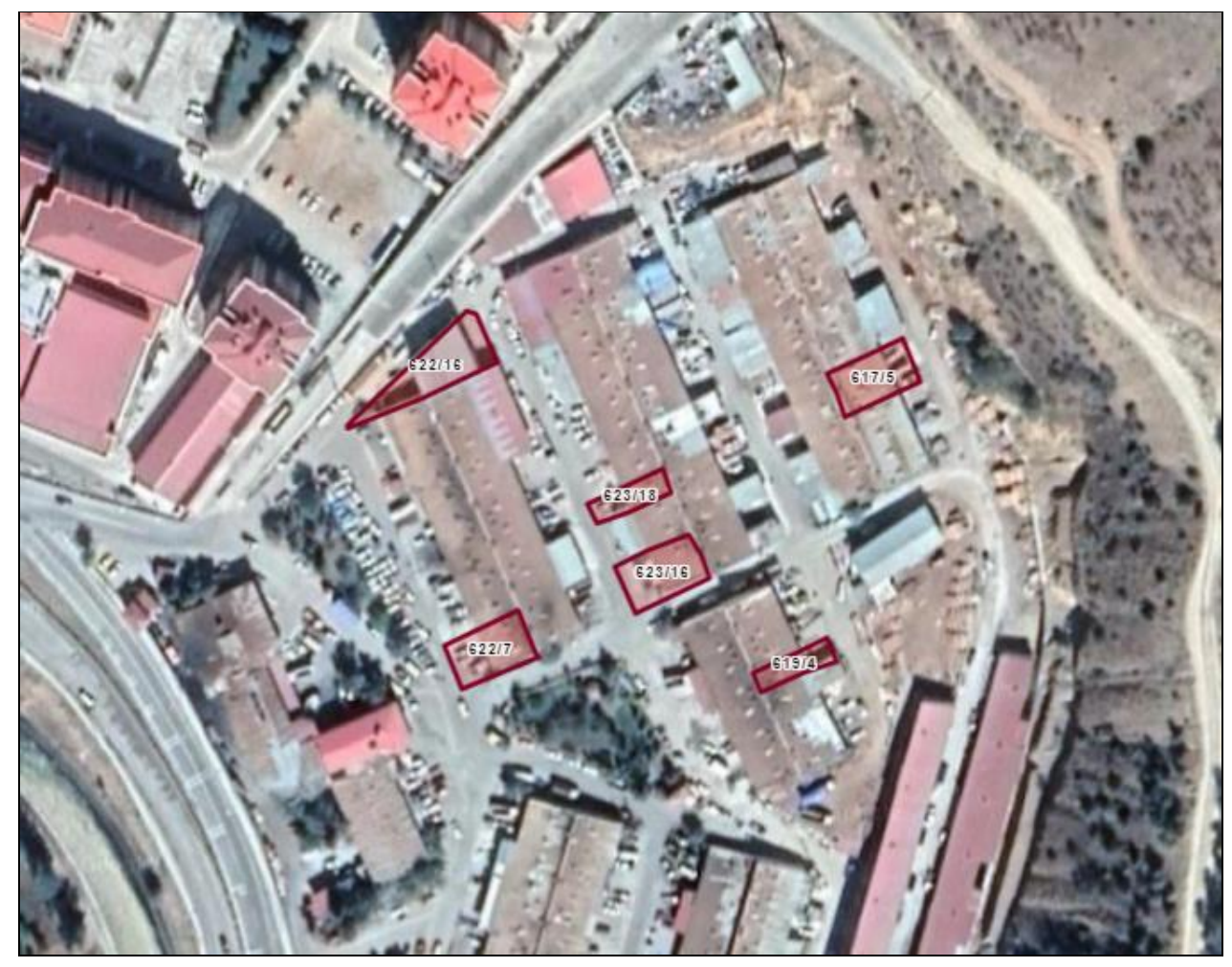

Şekil 2. Sanayi alanı değerlemesi yapılan Gümüşhane İli, Merkez, Bağlarbaşı Mahallesi sanayi alanında emsal alınan parsellerin Google Earth görüntüsü

Figure 2. Google Earth image of peer land parcels for industrial area of Gumushane Province, Central County, Baglarbasi District where industrial land parcel valuation is conducted. 


\subsection{Gayrimenkul değerlemesi yöntemleri}

\subsection{Real estate valuation methods}

Gayrimenkulün değerini belirlemek için genellikle gelir, maliyet ve karşılaştırma yöntemleri kullanılmaktadır. Değerleme yöntemi, gayrimenkul piyasasının alışkanlıkları ve taşınmaz konumuna göre belirlenebilmektedir (Açlar \& Çağdaş, 2008). İmar parsellerinde yapı bulunması halinde değer piyasa sürüm değerlerine göre belirlenir. Taşınmazın değerini belirlenmede, elimizde kullanılabilecek gerçek satışı ifade eden emsal değerlerin bulunmas1 durumunda karşılaştırma yöntemi kullanılmalıdır. Gelir yöntemi kullanılarak taşınmaz değerinin belirlenmesi, işyeri ve konut olarak kullanılan taşınmazdan elde edilecek gelire göre hesap yapılması gerekir. Üzerinde işhanı, fabrika vb. yap1 bulunan ve kira gelirleri bilinmeyen gayrimenkullerin değeri maliyet yöntemi kullanilarak bulunur (Deveci \& Y1lmaz, 2009).

Gayrimenkullerin veri seti şeklinde, toplu olarak değerlemesi yapılmasında konumsal özellikler önemlidir. Değerlemede konumsal etkilerin analizinde CBS destekli modeller kullanılmaktadır. Kentsel alan düzenlemelerinde taşınmazların gerçek değerlerini esas alan eşdeğer dağıtım modellerine yönelik değer belirlenmesi çalışmaları yapılmaktadır (Mete \& Yomralıoğlu, 2019).

Gayrimenkul değerlemesinde, 3 geleneksel yöntem uygulanabilmesi yönünden tercih edilmektedir. $\mathrm{Bu}$ yöntemler; emsal gösterme yöntemi, maliyet yöntemi ve gelir kapitalizasyonu yöntemidir. Verilen kiyaslanabilmesi nedeniyle, gayrimenkullerin değerlemesinde emsal yöntemi tercih edilmektedir. Gelir yöntemi ticari gayrimenkullerde kullanılırken, maliyet yöntemi daha çok yeni inşa faaliyetlerinde kullanılmaktadır (Akkaynak, B., 2017). Yöntem olarak emsal yöntemi tercih etmiş ise ayrıca arsa bedeli tespit edilmesine gerek olmazken, maliyet veya gelir yöntemine göre değerleme yapılması durumunda arsa bedelinin belirlenmesi gerekir (Yomralıoğlu vd., 2011).

Kentteki sanayi alanına isabet eden gayrimenkul ile konut alanına karşılık gelen gayrimenkullerin değerleri farklı olmaktadır. Sanayi tanımlı alanlarda depolama hacmi önemli olduğundan € $/ \mathrm{m}^{3}$ hacim kullanılırken, konut alanı tanımlı yerlerde birim inşaat $€ / \mathrm{m}^{2}$ kullanılmaktadır. Gelir yöntemi, gayrimenkulden elde edilecek gelirinin tahmini şeklindedir. Maliyet yöntemi ise bir yapının yeniden yapım maliyeti dikkate alınarak belirlenir. Yöntem, yüklenici yöntemi olarak da bilinmektedir.

\section{Uygulama (Bulgular) \\ 3. Application (Results)}

\subsection{Karşılaştırma yöntemine göre değer hesabı} 3.1. Valuation by peer comparison method

Karşılaştırma yönteminin uygulanabilmesi için güvenilir piyasa koşullarında satışı yapılan taşınmazların varlığıdır. Değerlemeye konu gayrimenkulün güncel satış değerlerinin emsalleriyle karşılaştırılmasıyla tespit edilmesidir. Güncel satış değerlerinin bulunmadığ durumlarda TÜİK verileri kullanılarak günümüzdeki değere yaklaşım sağlanmaktadır. Arsaların değerlemesi emsal alınan daha önceki satışlar kullanılarak göre yapılabilmektedir. Karşılaştırma yönteminin uygulanması, değerlemesi yapılacak parsele emsal kabul edilecek parsellerin belli tarihlerdeki alımsatım bilgileri ve imar özelliklerinin bilinmesine bağlıdır. Karşılaştırma yöntemine göre yapılan değerlemede, işlem yapılacak parselin mahallesinde güncel alım-satım değerleri dikkate alınmalıdır (Yomralığlu vd., 2011). Değerlemesi yapılacak parselin öz nitelikleri, emsal parsellerden farkl1lıklar göstermesi halinde, oluşan olumlu ve olumsuz etkilerin dikkate alınmasıyla gerçekçi değere yaklaşılması gerekmektedir.

Karşılaştırma ile değer belirlemesinde bölgede, yani mahallesinde karşılaş̧ırmaya uygun taşınmazların bulunması gerekmektedir. Aynı zamanda piyasa değerlerini yansitması önem arz etmektedir. Karşılaştırma yapılabilmesi için emsal alınan gayrimenkulün özellikleri ile değeri belirlenecek gayrimenkulün özelliklerinin benzer olması gerekmektedir. Konut bölgesindeki bir taşınmazın emsalinin konut bölgesinde, sanayi bölgesinin emsali sanayi bölgesinden seçilmesi gerekmektedir. Arsa üzerinde yap1 olması halinde parsel boyutları, imar planındaki şekli, kentteki konumu, tanımlanan işlevi, TAKS, KAKS değerleri, toplam inşaat alanı, ulaşım olanakları, kültürel donatılara yakınlığı, yapının türü, yapı tarzı, tasarımı, yeşil enerji yatırımı, yaşı, güncel durumu ve büyüklügüü, vb. öznitelik bilgileridir (Karakuş vd., 2011). Değerlemede, taşınmazda yapılanma koşulları, kentsel fonksiyon, topografya, manzara, taşınmazdaki haklar ve kısitlıklar gibi belirgin özelliklerinin belirtilmesi gerekir (Deveci \& Y1lmaz, 2009). Değerleme yapılırken karşılaştırma yapılan örneklemeler aynı gruptan olmak zorundadır. Örnek olarak uygulama imar planında konut bölgesindeki taşınmazlar ile sanayi alanına isabet eden taşınmazların 
değerlendirilmesinde her iki gruba ait emsal araştırması yapılması gerekmektedir.

\subsubsection{Konut bölgesinde değer hesabı \\ 3.1.1. Valuation for residential area}

Karşılaştırma yöntemi kullanılarak gayrimenkulün bugünkü değerinin bulunmasına, yakın zamanda satışı yapılan benzer taşınmazların özellikleri ve piyasa verileri elde edilir. Karşılaștırma yöntemini kullanarak taşınmazın değerinin bulunmasını bir örnek üzerinde inceleyebiliriz. Konut bölgesindeki karşılaştırma yönteminde elde edilen emsal değerlerin ortalaması alınır ve verilerin ortalamadan ne kadar saptığına bakılır. Emsallerin ortalama değerden sapma miktarını $\pm \% 15$ kabul ederek standart sapma değeri hesaplanır. Bu değerin küçük veya büyük olması sayılar arasındaki konumları değerlendirmemize yarar. Büyük olması güvensizlik sayılar arasında uçurum olduğunu gösterir. Standart sapmanın küçük çıkması emsal değerlerinin birbirine çok yakın olduğunu gösterir. Örnek uygulamada standart sapma (sınır değer) \%15 alınmıştır. Emsal alınan satışların tamamı konut bölgesinden seçilmiştir. Konut bölgesindeki taşınmazın değerinin belirlenmesinde Tablo 1'de verilen Tüketici Fiyat Endeksi ve Değişim Oranı $(2003=100)$ endeks değerleri kullanılarak, Tablo 2'de verilen satış değerleri değeri belirlenecek zamana taşınmaktadır.

Tablo 1. Taşınmazların satış tarihlerindeki Tüketici Fiyat Endeksi ve Değişim Oranı $(2003=100)$ endeks değerleri tablosu

Table 1. Consumer Price Index and Change Rate $(2003=100)$ index values table on the date of real estate transactions

\begin{tabular}{ccccccc}
\hline TARİH & Şubat 2016 & Haziran 2016 & Ekim 2017 & Mayıs 2018 & Ağustos 2018 & Aralık 2018 \\
\hline 2003=100 ENDEKSİ & 274.38 & 279.33 & 320.40 & 348.34 & 367.66 & 393.88 \\
\hline
\end{tabular}

Tablo 2. Emsal taşınmazlar tablosu

Table 2. Peer real estates table

\begin{tabular}{cccccccc}
\hline $\begin{array}{c}\text { Konut arsasi için } \\
\text { emsaller }\end{array}$ & $\begin{array}{c}\text { Ada/ } \\
\text { Parsel }\end{array}$ & $\begin{array}{c}\text { Alan } \\
\left(\mathbf{m}^{2}\right)\end{array}$ & Emsal & $\begin{array}{c}\text { Değer } \\
(\mathbf{t})\end{array}$ & Tarih & $\begin{array}{c}\text { Satış Birim } \\
\text { Değeri }\left(\boldsymbol{\hbar} / \mathbf{m}^{2}\right)\end{array}$ & $\begin{array}{c}\text { Güncel Birim } \\
\text { Değeri }\left(\boldsymbol{\sharp} / \mathbf{m}^{2}\right)\end{array}$ \\
\hline Emsal 1 & $11400 / 11$ & 1145.00 & 2.00 & 1.700 .000 & 16.01 .2016 & 742.36 & 1.065 .68 \\
Emsal 2 & $11401 / 5$ & 502.00 & 1.50 & 560.000 & 10.06 .2016 & 743.69 & 1.048 .67 \\
Emsal 3 & $11400 / 4$ & 1580.00 & 2.00 & 2.750 .000 & 07.11 .2017 & 870.25 & 1.069 .83 \\
Emsal 4 & $11403 / 13$ & 843.76 & 1.80 & 1.300 .000 & 25.05 .2018 & 855.96 & 967.86 \\
Emsal 5 & $11401 / 6$ & 843.00 & 1.50 & 1.050 .000 & 29.09 .2018 & 830.37 & 889.59 \\
D. Konu & $11403 / 8$ & 1940.66 & 1.80 & $?$ & 15.12 .2018 & & \\
Parsel & & & & & & & \\
\hline
\end{tabular}

Değerin bulunabilmesi için önceki tarihli satışların güncel değerlerinin bulunmasına ihtiyaç vardır. Bunun için Tüketici Fiyat Endeks değerleri kullanılarak değerleme gününe gelinmesi gerekmektedir. Çünkü, yıllık enflasyon değerindeki değişimi ölçmek için kullanılır. TÜFE'de esas alınan perakende fiyatlarıdır. Aralık
2018 satıș değeri (1) formülünden yararlanılarak bulunmaktadır. Emsal 1 için yapacak olursak $393.88 / 274.38=1.435527371$ katsayıs elde edilmektedir. Bulunan değer satıș bedeli ile çarpılırsa $742.36^{*} 1.435527371=1.065 .68 €$ olmaktadır. Emsal satışları gösteren pafta Şekil 3'te verilmektedir.

Satış tarihi değeri $=$ Önceki tarihli satış de $\breve{g}$ eri $* \frac{\text { Arallk } 2018 \text { Endeksi }}{\text { Şubat } 2016 \text { Endeksi }}$

Emsal (KAKS): yapının katlar alanı toplamının imar parseli alanına oranıdır. Değerlemeye emsal alınan arsaların değerinden $1 \mathrm{~m}^{2}$ inşaat yapılabilen arsa alanı değerini bulabiliriz. Emsal satıș 1

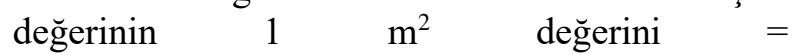
$1.700 .000 /(1145 * 2.00)=742.36 \quad € / \mathrm{m}^{2} \quad$ şeklinde bulabilir. Diğer satışların da benzer şekilde $\mathrm{m}^{2}$ birim bedelini belirleyebiliriz. Bölgede 5 emsal satışın günümüze çevrilmiş satış bedelleri dikkate alındığında ortalama taşınmaz fiyatı $1.008 .33 € / \mathrm{m}^{2}$ olmaktadır. Uyumsuz değerlerin belirlenmesi için $\% 15$ sinır değere göre hesaplama yapıldığında üst sinır $\left(1.008 .28 € / \mathrm{m}^{2}\right)^{*}(1+\% 15)=1.159 .52 €$ ve alt sinır $\quad\left(1.008 .28 \quad € / \mathrm{m}^{2}\right)^{*}(1-\% 15)=\quad 857.04 €$ 
olmaktadır. Elde edilen $\mathrm{m}^{2}$ veriler sınır değerlerin arasında kaldığından ortalama alınarak hesap yapılabilir. $\mathrm{Bu}$ durumda Taşınmazın değeri= Değerlenecek parselin toplam inşaat alanı*Emsal şeklinde olmaktadır. Değerlenecek taşınmazın satış değeri $\quad 1.940 .66 \mathrm{~m}^{2 *} 1.80 * 1.008 .28 € / \mathrm{m}^{2}=$ 3.522.104.61€ olmaktadır.

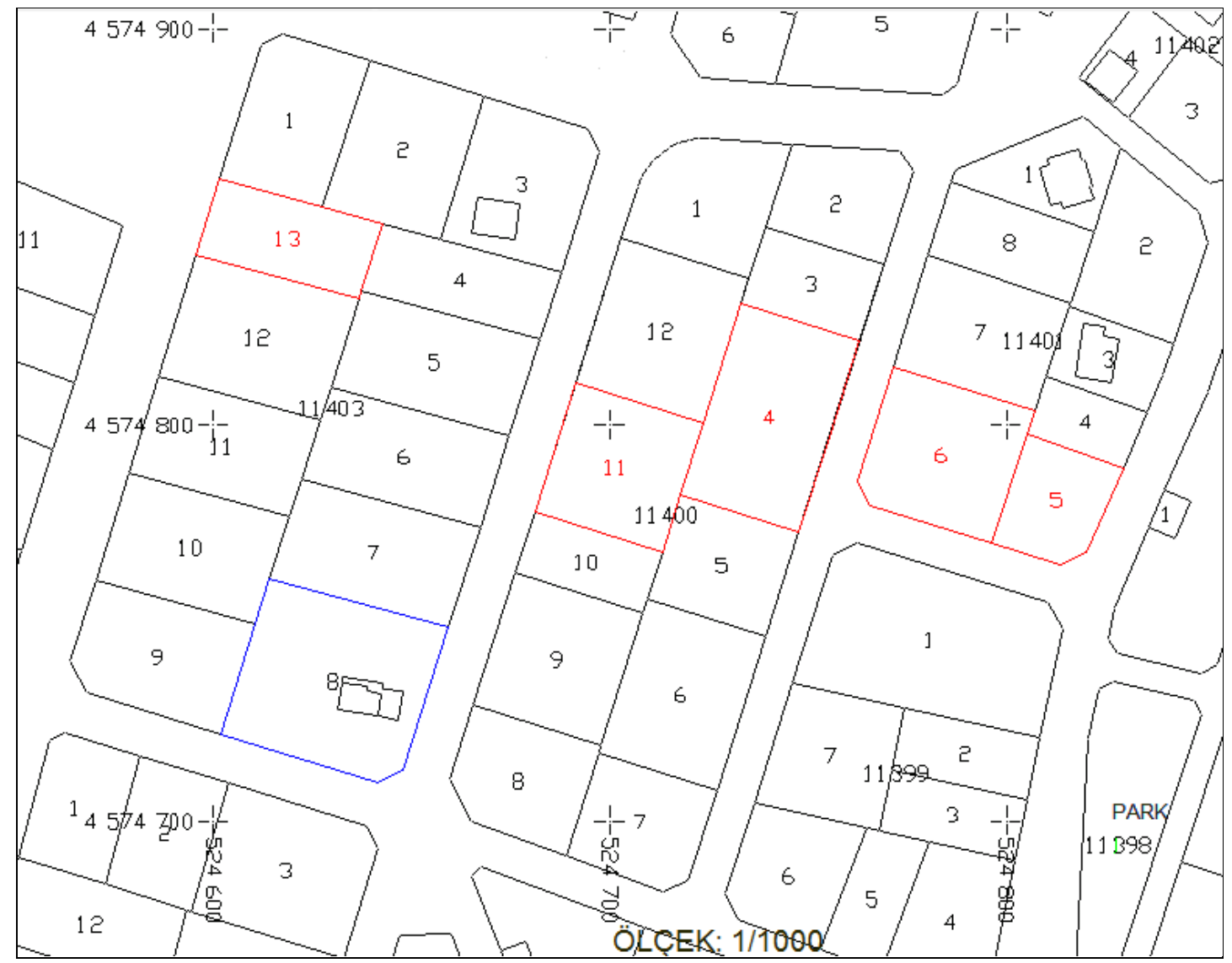

Şekil 3. Konut Bölgesindeki emsal satışları gösteren F42-B-16-C-3-B pafta örneği (Not: Makale formatı nedeniyle harita ölçekli yerleştirilememiştir)

Figure 3. F42-B-16-C-3-B map sheet sample showing peer transactions on Residential Area (Note: The map sheet is not presented by its original scale due to manuscript format)

\subsubsection{Sanayi bölgesinde değer hesabı}

\subsubsection{Valuation for industrial area}

Sanayi bölgesinde yapılacak bir değerleme işleminde 1223 ada 7 nolu parselin değeri daha önceden bilinen Emsal 1, Emsal 2, Emsal 3, Emsal 4 ve Emsal 5 parsellerine ait yapılanma koşulları dikkate alınarak hesaplama yapılmıştır. Satış bedellerini değerleme gününe dönüştürmek için
TÜIKK verileri kullanılmıștır. Tüketici fiyat endeks rakamları $(2003=100)$ değişim oranı endeks değerleri Tablo 3'teki gibidir. Sınır kontrolleri olarak \%15 değeri kullanılarak hesaplama yapılacaktır. Sanayi bölgesi için emsal alınan satışların Tablo 4'te verilen satış değerleri günümüze yani değeri belirlenecek zamana taşınmaktadır.

Tablo 3. Taşınmazların satış tarihlerindeki endeks değerleri tablosu

Table 3. Index values table on the date of real estate transactions

\begin{tabular}{ccccccc}
\hline Tarih & Eylül 2012 & Mart 2015 & Temmuz 2017 & Kasım 2018 & Ocak 2019 & Mayıs 2020 \\
\hline 2003=100 Endeksi & 207.55 & 255.23 & 310.24 & 395.48 & 398.07 & 460.62 \\
\hline
\end{tabular}


Tablo 4. Emsal taşınmazlar tablosu

Table 4. Peer real estates table

\begin{tabular}{|c|c|c|c|c|c|c|c|c|c|}
\hline $\begin{array}{l}\text { Sanayi Arsası } \\
\text { için Emsaller }\end{array}$ & $\begin{array}{l}\text { Ada/ } \\
\text { Parsel }\end{array}$ & $\begin{array}{c}\text { Alan } \\
\left(\mathbf{m}^{2}\right)\end{array}$ & $\begin{array}{c}\text { Yük. } \\
\text { (h) }\end{array}$ & $\begin{array}{l}\text { Değer } \\
(\mathbf{f})\end{array}$ & Emsal & Tarih & $\begin{array}{c}\text { Güncel } \\
\text { Değer } \\
\text { (I) }\end{array}$ & $\underset{\left(\mathbf{m}^{3}\right)}{\text { Hacim }}$ & $\begin{array}{l}\text { Bihd } \\
\mathbf{E} / \mathbf{m}^{3}\end{array}$ \\
\hline Emsal 6 & $623 / 16$ & 328.40 & 6.50 & 450.000 & 0.50 & 16.08 .2012 & 998.694 .29 & 1.067 .30 & 935.72 \\
\hline Emsal 7 & $623 / 18$ & 152.66 & 6.50 & 250.000 & 0.50 & 27.02 .2015 & 451.181 .29 & 496.15 & 909.36 \\
\hline Emsal 8 & $617 / 5$ & 305.95 & 6.50 & 600.000 & 0.50 & 21.06 .2017 & 890.832 .90 & 994.34 & 895.90 \\
\hline Emsal 9 & $619 / 4$ & 153.16 & 6.50 & 350.000 & 0.50 & 20.10 .2018 & 407.648 .93 & 497.77 & 818.95 \\
\hline Emsal 10 & $622 / 7$ & 326.51 & 6.50 & 850.000 & 0.50 & 19.12.2019 & 983.563 .19 & 1.061 .16 & 926.88 \\
\hline $\begin{array}{l}\text { D. Konu } \\
\text { Parsel }\end{array}$ & $622 / 16$ & 408.37 & 6.50 & $?$ & 0.50 & 27.04 .2020 & $?$ & 1.327 .20 & \\
\hline
\end{tabular}

Değerin bulunabilmesi için önceki tarihli satışların güncel değerlerinin bulunmasına ihtiyaç vardır. Bunun için Tüketici fiyat endeks değerleri kullanılarak değerleme gününe gelinmesi gerekmektedir. Mayıs 2020 satış değeri= Önceki tarihli satış değer* (Mayıs 2020/Eylül 2012) şeklinde bulunmaktadır. Değeri belirlenecek arsa sanayi bölgesinde yer aldığ 1 için birim inşaat hacmi kullanılarak çözüme gidilmesi gerekmektedir (Bal, 2018). Birim inşaat hacmi değeri (2) formülündeki gibi hesaplanmaktadır. Emsaller için birim inşaat hacmi değeri hesaplamaları Tablo 4'te gösterilmiştir. $\mathrm{Bu}$ değerlerin ortalaması alınarak ortalama Birim İnşaat Hacmi Değeri(BİHD) = $(935.72+909.36+895.90+818.95+926.88) / 5=$

Birim İnşaat Hacmi Değeri= $=\frac{\text { Toplam Güncel Değer }}{\text { Toplam İnşaat Hacmi }}$

\subsection{Gelir yaklaşımı yöntemi}

\subsection{Income approach method}

Gayrimenkullerin değeri getirdikleri gelire göre belirlenebiliyorsa piyasa sürüm bedellerinin bulunması için gelir yönteminin kullanılması kuraldır. Gelir yaklaşımı yönteminde üzerinde yap1 bulunan bir gayrimenkulün değerinin belirlenmesinde esas ölçüt, gayrimenkulden elde edilebilecek net gelirdir. Gayrimenkuldeki net gelir, yapıdan elde edilen gelir, yapıya ilişkin diğer yapısal tesislerin getirisi ve arsa payından oluşur. Arsalar sürekli olarak kullanılırken, yapıların kullanım süreleri yıpranması nedeniyle sınırlıdır. $\mathrm{Bu}$ nedenle net gelirin akçesel karşıllı̆ının saptanmasında arsa, yapı ve yapıya ilişkin diğer yapısal tesislerin değerleri ayrı kısımlarda belirlenir (Deveci \& Y1lmaz, 2009).

Gelir yaklaşımı yöntemi, gayrimenkuldeki yıllık gelir miktarının tahmin edilmesi esasına dayanır. Gelir yaklaşımında gayrimenkulün şimdiki geliri ve gelecekteki geliri birbirine denk olmaktadır. Değer, gayrimenkulün kullanılabilir ömrü boyunca
$897.36 € / \mathrm{m}^{3}$ olarak bulunur. Sanayi bölgesinde de elde edilen ortalama değer alınır ve eldeki verilerden kullanılarak ortalamadan ne kadar saptığına bakılır. Üst sınır değer $897.36 *(1+0.15)$ $=1.031 .96 € / \mathrm{m}^{3}$ ve alt sinır $897.36 *(1-0.15)=$ $762.76 £ / \mathrm{m}^{3}$ olmaktadır. $\mathrm{Bu}$ durumda sanayi parselleri için alınan emsal parsellerin tamamı kullanılarak ortalama Birim İnşaat Hacmi Değeri $897.36 € / \mathrm{m}^{3}$ olarak bulunur. Sanayi bölgesindeki 622 ada 16 nolu parselin değeri = $408.37 * 0.50 * 6.50 * 897.36 € / \mathrm{m}^{3}=1.190 .978 .44 €$ olmaktadır. Sanayi bölgesindeki emsal satışları gösteren Gümüşhane İli, Merkez, Bağlarbaş1 Mahallesi, 1/1000 ölçekli H43-A-06-A-2-C nolu pafta örneği Şekil 4'te gösterilmektedir.

yaratacağı toplam gelirlerin bugünkü karşılığıdır. Gelir yaklaşımı yönteminde düzenli olarak elde edilebilen gelir dikkate alınmaktadır. Aynı zamanda gelir; taşınmazın " $\mathrm{t}$ " zamanında elde edileceği varsayılan bütün gelirlerini kapsar ve değerin belirleneceği gündeki değere indirgenmesini ifade eder. Başka bir deyişle gelir yaklaşımı yöntemi; aynı zamanda bir kapitalizasyon tekniğini içerir. Hesaplamada dikkate alınması gerekli olan net gelirdir. Net gelir hesab1, "yillık brüt gelirden ylllk toplam masrafların çıkarılmasıyla bulunur. Bu bağlamda taşınmazın değeri; (3) formülünden yararlanılarak hesaplanır" (Açlar \& Çağdaş, 2008).

Değer $=\frac{\text { Ylllık Net Gelir }}{\text { Kapitalizasyon Oranı }}$

Gelir yaklaşımı yöntemi, yapılaşmasını tamamlamış alanlarda apartmanlar, iş hanları ve dükkânlar gibi kira getiren yapılar için uygun yaklaşım gösterir. Gelir yaklaşımı yönteminin kullanılması için ön koşul, pazara uygun taşınmaz faiz miktarının bilinmesidir (Ertaş, 2000). 
Gelir yaklaşımında, gayrimenkulün gelecekte gelir getirme kapasitesi ölçülür. Beklenti ilkesi gelir yaklaşımının temel öğesidir. Gelir getiren gayrimenkulün getirisi ne kadar yüksek ise değeri de o kadar yüksek olmaktadır. Karşılaştırma yöntemi ve maliyet yönteminde olduğu gibi ilgili karşılaştırılabilir veriler olduğunda kullanılabilmektedir. Gelir yönteminde kullanılan temel veriler ve bulunacak kurumlar aşağıdaki gibidir. Tapu ve Kadastro Genel Müdürlüğü’nden tapu ve kadastro verileri, yerel piyasa fiziksel incelemesi ile brüt gelir, piyasada fiziksel inceleme net gelir ve tapu müdürlüğünden son satış fiyatlarının alınması gerekmektedir. Gelir yaklaşımı kullanılarak kiralama işlemlerinde kiranın normal koşullarda olup olmadığı değerlendirilebilmektedir.

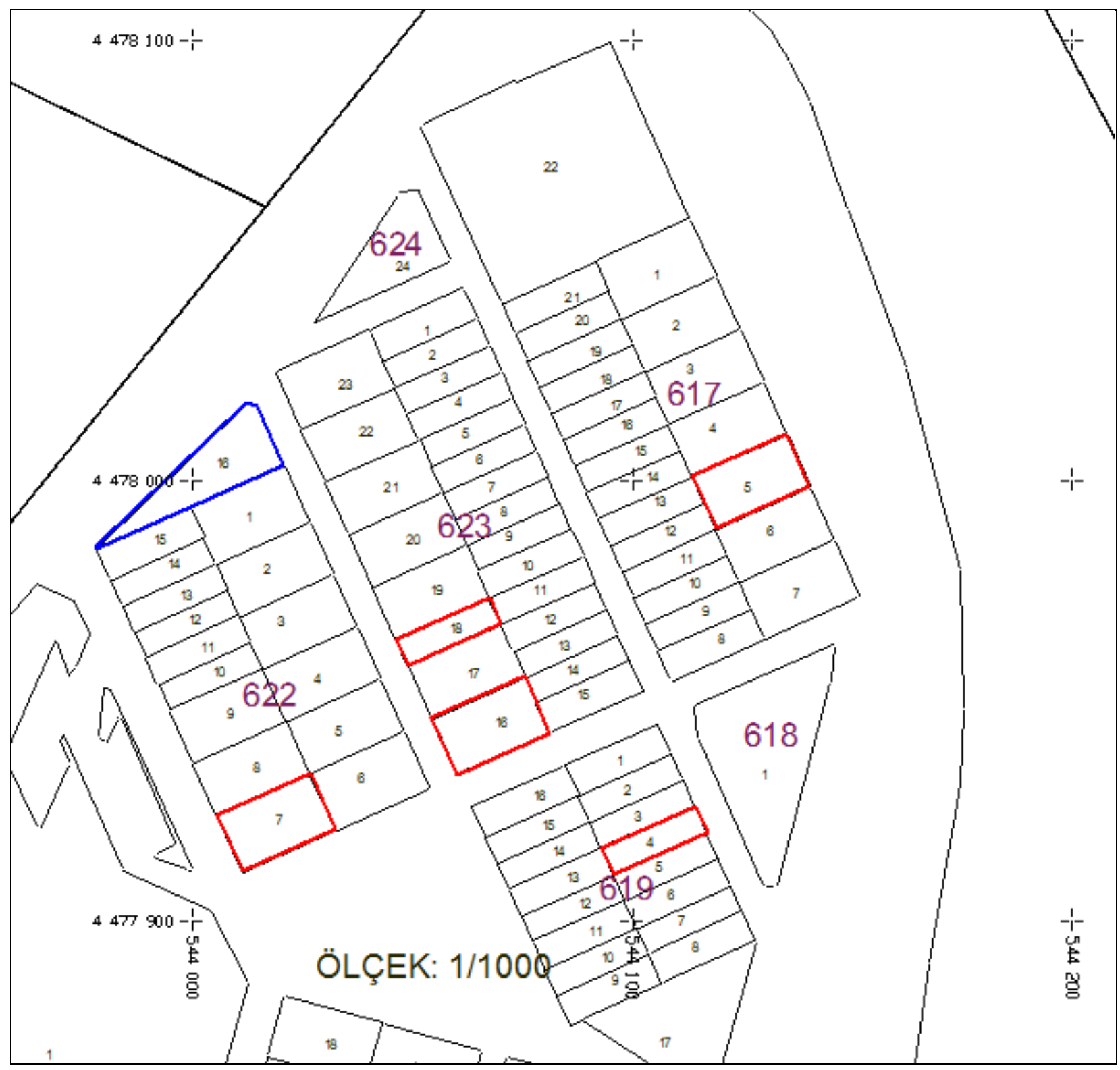

Şekil 4. Gümüşhane İli, Merkez, Bağlarbaşı Mahallesi, Sanayi bölgesindeki emsal satışları gösteren 1/1000 ölçekli H43-A-06-A-2-C nolu pafta örneği

Figure 4. 1/1000 scale H43-A-O6-A-2-C map sheet sample showing peer transactions on industrial region of Baglarbasi District, Central County, Gumushane Province. 
Tablo 5. Emsal taşınmazlar tablosu

Table 5. Peer real estates table

\begin{tabular}{|c|c|c|c|c|c|}
\hline Veri & Niteliği & $\operatorname{Alan}\left(m^{2}\right)$ & Katı & Kira(志/yıl) & $\begin{array}{l}\text { Birim kira değeri } \\
\mathbf{E} /\left(\mathbf{m}^{2}\right)\end{array}$ \\
\hline Emsal 11 & Konut/Daire & 150 & 2.KAT & 10.500 .00 & 70.00 \\
\hline Emsal 12 & Konut/Daire & 180 & 3.KAT & 14.400 .00 & 80.00 \\
\hline Emsal 13 & Konut/Daire & 125 & 5.KAT & 10.200 .00 & 81.60 \\
\hline Emsal 14 & Ticaret/Ofis & 120 & 1.KAT & 24.000 .00 & 200.00 \\
\hline Emsal 15 & Konut/Daire & 145 & 4.KAT & 12.000 .00 & 82.76 \\
\hline Konu daire & Konut/Daire & 160 & 5.KAT & $?$ & \\
\hline
\end{tabular}

Emsal veriler irdelendiğinde kira değeri bulunacak taşınmazın daire olduğu görülmektedir. Dolayısıyla emsal 14'ün ofis olması ve ticari bir faaliyet içermesi nedeniyle hesaplamada kullanılmaması gerekir. Geriye kalan konut kullanımlı kira bedellerinin ortalama kira değeri $78.59 € / \mathrm{m}^{2}$ olmaktadır. Dolayısıyla gelir yaklaşımı yöntemi ile kira bedeli bilinmeyen dairenin yıllık kiras1 $160 * 78.59=12.574 .40(\varsubsetneqq / Y I L)$ olmaktadır. Y1llık kiraya ek olarak konu daire değerinin

Daire Değeri= Aylık Brüt Gelir * Brüt Kira Gelir Çarpanı bulunması; yakın zamanda satılmış olan emsal dairelerin satış fiyatları ve kira gelirlerinin oranlanması ile bulunan brüt kira gelir çarpanının bulunması (4) formülü ile bulunmaktadır. Aylık brüt gelir ile brüt kira gelir çarpanının çarpılması sonucunda daire değeri hesaplanabilmektedir. Emsal alınan dairelerin satış değerleri bilinmediğinden Tablo 5 'teki örneğimizde dairenin kira değerine ulaşılabilmektedir.

Brüt Kira Gelir Çarpanı $=\frac{\text { Emsal } \text { Taşınmaz Satış Fiyatı }}{\text { Aylık Kira }}$

\subsection{Maliyet yaklaşımı yöntemi}

\subsection{Cost approach method}

Maliyet yöntemi, bir yapının yeniden üretilmesi bedeline dayanmaktadır. Yöntem, yüklenici yöntemi olarak da bilinmektedir. Bu yöntem fabrika, otel, işhanı, sanayi sitesi, konut, idari yapılar vb. üzerinde yap1 bulunan kira geliri bilinmeyen gayrimenkullerin değerlemesinde kullanılır. Maliyet yaklaşımı yöntemi; belirli bir gayrimenkulün satın alınması yerine kişinin ya o gayrimenkulün birebir aynısını ya da aynı yararı sağlayacak başka bir gayrimenkulü inşa edebileceği olasılığını dikkate alır (Öztürk vd., 2011). 1319 sayılı Emlak Vergisi Kanunu ve 2942 sayılı Kamulaştırma Kanunu yapılı gayrimenkullere değer belirlenmesini öngörmektedir. Maliyet yaklaşımı yöntemi, yeni veya çok az yıpranmış inşaatların değerlemesinde kullanılır. Maliyet yaklaşımı yöntemi, özellikle yapı değerlerinin ayrı ayrı belirlendiği sigortacılık uygulamalarında oldukça kullanılışlıdır. Piyasa değeri (5) eşitliği kullanılarak hesaplanmaktadır.

\section{Piyasa Değeri= $=($ İnşaat Maliyeti + Girişimci Karı - Amortisman $)+$ Arsa Değeri $\rfloor$}

Maliyet yaklaşımının kullanım alanları aşağıdaki gibidir.

- Piyasa koşullarında alım-satımı sık yapılmayan gayrimenkullerin değerlemesinde,

- Taşınmazlara ait karşılaştırılabilir satış bilgisi olmadığında,

- Özel kullanımı olan yapılarda,

- Taşınmazın gelir getiren bir mülk cinsi olmadığında,

- Alışılagelmişin dışında bir mülk olduğunda veya çok yavaş bir pazar söz konusu olduğunda,

- Yarım kalmış veya proje aşamasındaki projelerin değerleme çalışmalarında,
- Taşınmazda eklentiler ve yenilemeler söz konusu olduğunda,

- Gayrimenkulün arsa ve yapısının ayrı ayrı değerlendirilmesi gerekli durumlarda,

- Değerlemeye esas emsal satış bilgilerinin yetersiz olması durumlarında,

Karşılaştırmalı satış analizi yönteminde bazı kalemlerin parasal düzeltmelerinde maliyet yaklaşımı yöntemini kullanmak uygun düşmektedir (Rehber, 2008; Gümüş vd., 2017).

Yapının yeni olarak üretim maliyeti; değerleme tarihinde mümkün olduğunca aynı malzeme, inşaat standartları, tasarımlar, vaziyet planı ve işçilik kalitesini kullanarak, değerlemeye konu olan 
binanın bütün kusurlarını, yetersizliklerini ve yıpranma paylarını muhafaza ederek, değerlemesi yapılan yapının aynısını yeni inşa etmenin maliyeti olarak tanımlanmaktadır. Yeniden üretme veya inşa etme maliyeti; aynı tasarım, aynı inşaat malzemeleri ve işçilik kalitesi ile orijinal yapının aynısının üretilmesi maliyettir. Maliyet yaklaşımı yöntemi, teorik olarak yeniden inşa etme maliyetini esas almaktadır. Örnek olarak; değeri 150.000.00 olan bir arsa üzerindeki 10 yaşındaki binanın yeniden yapılma maliyeti $250.000 .00 €$ 'dir. 6-10 yaş arası binalarda yıpranma oranı \%12 olduğuna göre mülkün piyasa değerini (6) formülü ile bulabiliriz.

Piyasa Değeri=[(Yeni Yapı Değeri-Amortisman )+Arsa Değeri]

(6) formülü kullanılarak işlem yapıldığında; Piyasa Değeri $=250.000-30.000+150,000=370.000 .00 €$ olarak bulunmaktadır.

\section{Tartışma ve sonuçlar}

\section{Discussion and conclusions}

Gayrimenkul değerlemesi yapılarak, gayrimenkul projesinin veya gayrimenkule bağlı hak ve faydaların belli bir tarihteki muhtemel değerinin bağımsız ve tarafsız olarak takdir edilmesi objektif ölçütler kullanılarak yapılabilmektedir. Gayrimenkul değerlemesinde önemli olan uygun bir taşınmaz değerleme yöntemini seçmektir. Yapılan değerleme işlemlerinde gerçek değere ulaşmak hemen hemen imkansızdır. Yapılan çalışmalar gerçek değere en çok yaklaşanı bulma şeklindedir. $\mathrm{Bu}$ yöntemler bazen satın alma işleminde kullanılırken, bazen de taşınmazın kira gelirinin belirlenmesinde, ipotekli kredi kullanım limitinin belirlenmesi için de kullanılabilmektedir. Diğer yandan eldeki taşınmazın konut veya farklı şekilde değerlendirme veya satılacak taşınmaz hakkında genel bir bilgi veren yöntemlerdir. $\mathrm{Bu}$ çalışmada; karşılaştırma yöntemi, gelir yaklaşımı yöntemi ve maliyet yaklaşımı yöntemi ele alınarak örnekler verilmiştir. Karşılaştırma yönteminde konut ve sanayi bölgesinde bulunan gayrimenkullere değerleme örnekleri verilmiştir. Taşınmazların değerinin güncel belirlenmesi sonucunda devletin vergi geliri artacaktır. Gayrimenkul değerlerinin bilinmesi vergi adaletinin sağlanmasına katkı sağlayacaktır. Taşınmazların değerinin belirlenmesinde parsel öznitelikleri bilgisi ve bölgede oluşan değer bilgilerine ihtiyaç bulunmaktadır. Değerleme için verilerin toplanması halinde il, ilçe, mahalle, mevkii bazında değer haritalarının üretilmesi mümkün hale gelecektir. Değer haritalarının oluşturulması halinde kamulaştırma yapacak ve değere ihtiyacı olan kurum ve kuruluşların bütçe giderleri gerçekçi belirlenebilecektir. Yapılan çalışmada Samsun İli, Atakum İlçesi, Büyükkolpınar Mahallesi ve Gümüşhane İli, Merkez, Bağlarbaşı Mahallesinde konut ve sanayi alanlarında değerleme çalışması yapılarak satış değeri verileri elde edilmiştir. Kentteki konut alanına isabet eden arsalar ile sanayi alanı tanımlı arsaların değerlerinin değerleme birimleri (alan/hacim) açısından farklı olduğu tartışılmıştır.

\section{Teşekkür \\ Acknowledgement}

Yazar, makalenin inceleme ve değerlendirme aşamasında yapmış oldukları katkılardan dolayı editör ve hakemlere teşekkür eder.

\section{Yazar katkısı}

\section{Author contribution}

$\mathrm{Bu}$ çalışmanın tasarım, hesaplamalar ve makale yazımı Kemal ÇELIK tarafindan gerçekleştirilmiştir.

\section{Etik beyanı}

Declaration of ethical code

$\mathrm{Bu}$ makalenin yazarı, bu çalışmada kullanılan materyal ve yöntemlerin etik kurul izni ve / veya yasal-özel izin gerektirmediğini beyan etmektedir.

\section{Çıkar çatışması beyanı \\ Conflicts of interest}

Yazar herhangi bir çıkar çatışması olmadığını beyan etmektedir.

\section{Kaynaklar \\ References}

Açlar, A. \& Çağdaş, V. (2008). SPK ve kamulaştırma değerleyicileri mühendis, mimar ve uzmanlar için taşınmaz (gayrimenkul) değerlemesi, TMMOB Harita ve Kadastro Mühendisleri Odası, ISBN: 978-9944-89-558-3, 113-124, Ankara.

Akkaynak, B. (2017). Gayrimenkul değerlemesi ve gayrimenkul değerlemesi üzerine bir uygulama, Sosyal Bilimler Dergisi / The Journal of Social Science, $\quad 18, \quad$ (18), $\quad 695-717$. https://doi.org/10.16990/SOBIDER.3898

Bal, H. (2018). Gayrimenkul değerleme esasları, SPK Lisanslama Sinavlarına Hazırlı, ISBN: 978- 
605-84350-2-5, Özdoğan Matbaa Yayın ve Hed. Eşya San. Tic. Ltd. Şti, Ankara

Bakanlar Kurulu Kararı, (1983). T.C. Resmî Gazete, $(17984,11 / 03 / 1983)$

Bin, O. (2004). A prediction comparison of housing sales prices by parametric versus semiparametric regressions, Journal of Housing Econoilcs, $\quad 13, \quad$ (1), 68-84, https://doi.org/10.1016/j.jhe.2004.01.001

Cupal, M. (2016). Price adjustments of price-setting factors under sales comparison approach (SCA), Global Journal of Business, Economics and Management: Current Issues, 6, (2), 164-170.

Cupal, M. (2017). Sales comparison approach indicating heterogeneity of particular type of real estate and corresponding valuation accuracy, Acta Universitatis Agriculturae et Silviculturae Mendelianae Brunensis, 65, (3): 977-985, https://doi.org/10.11118/actaun201765030977

Çelik, K. \& Aşık, Y. (2004). Emlak vergisi değerinin piyasa koşullarına göre belirlenmesi, Mülkiyet Dergisi, Tapu ve Kadastro Müfettişleri Derneği Yayın Organı, Sayı 52, Ankara

Çoşar, G. Ö. \& Engindeniz, S. 2011). Tarım arazilerinin değerlemesinde coğrafi bilgi sisteminden yararlanma olanakları, Ege Üniversitesi Ziraat Fakültesi Dergisi, 48(3): 283-290, ISSN 1018 8851, İzmir

Deveci, E. \& Yılmaz, İ. (2009) Coğrafi bilgi sistemleri yardımıyla taşınmaz mal değerlemesi: Afyonkarahisar il merkezi örneği, Harita Teknolojileri Elektronik Dergisi, 1(1), (33-47)

Donald, M. \& Jess, B. (1996). Unit selection and the sales comparison approach, Journal of Property Valuation \& Investment, 14(5), https://doi.org/10.1108/14635789610154262

Emlak Vergisi Kanunu, (1970). Yayımlandığı Düstur; Tertip:5 Cilt:9 Sayfa:2662, T.C. Resmî Gazete, $(13576,11 / 8 / 1970)$

Ertaş, M. (2000), Kentsel alanlarda taşınmaz mal değerlemesi, Doktora Tezi, İstanbul Teknik Üniversitesi, Fen Bilimleri Enstitüsü, İstanbul.

Farkas, A. \& Porumb, B. (2020). A multi-attribute sales comparison method for real estate valuation, Periodica Polytechnica Social and Management Sciences, 28(1), 1-11. https://doi.org/10.3311/PPso.13897

Gümüş, U. T., Sezer, D. \& Ulu, E. (2017). Kentsel alanlarda gayrimenkul değerlemesi ve aydın il merkezinde bölgesel kapitalizasyon oranının belirlenmesi, Ekonomi ve Yönetim Araştırmaları Dergisi, 6(1), 134 - 155.
IVSC (t.y.). We build trust in valuation. https://www.ivsc.org/

Hans, I. (2002). The linear algebra of the sales comparison approach, Journal of Real Estate Research, 24(2), 117-128. https://doi.org/10.1080/10835547.2002.1209109 0

İmar Kanunu, (1985). Yayımlandığı Düstur; Tertip: 5 Cilt: 24 Sayfa: 378, T.C. Resmî Gazete, (18749, 9/5/1985),

Karakuş H. H., Özdemir, T. \& Turabi, A. (2011). Kentsel alanlarda gayrimenkul değerlemesi ve Balıkesir il merkezinde bölgesel kapitalizasyon oranlarının belirlenmesi, Balıkesir Üniversitesi Fen Bilimleri Enstitüsü Dergisi, 13(2), 112-119.

Lisi, G. \& Iacobini, M. (2018). Estimating adjustment factors for the sales comparison approach in the presence of heterogeneous housing and thin markets, Journal Of Real Estate Research, 40(1), 89-120.

https://doi.org/10.1080/10835547.2018.1209149 3

Lisi, G. (2019). Sales comparison approach, multiple regression analysis and the implicit prices of housing. Journal of Property Research, 36(3), 272-290,

https://doi.org/10.1080/09599916.2019.1651755

Mekânsal Planlar Yapım Yönetmeliği, (2014). T.C. Resmi Gazete (29030, 14 Haziran 2014)

Mete, M. \& Yomralığlu, T. (2019). CBS ile nominal taşınmaz değer haritası üretiminde çözünürlük araştırması, Türkiyede Arazi Yönetimi Dergisi, 1(1), 16-23, e-ISSN:2687-5187

Munshifwa, E. K. (2021). An investigation into the use of "Hybrid" adjustment techniques in the application of the sales comparison method in residential valuation, Real Estate Management and Valuation, 29(1), 1-11. https://doi.org/10.2478/remav-2021-0001

Öztürk, M. (2017). Gelir getiren emlâk değerlemesi, Journal of Yasar University, 3(10), 1347-1367.

Rehber, E. (2008). Tarımsal kıymet takdiri (değerleme) ve bilirkişilik, Ekin Yayınları, Bursa.

RICS (t.y.). About us. https://www.rics.org/uk/aboutrics/

MingYou, S. and Chang, C. (2009). Weight regression model from the sales comparison approach, Property Management, 27(5), 302-318. https://doi.org/10.1108/02637470910998465

Taygır, T. \& Hacıköylü, C. (2018). Arsa ve arazilere yönelik mali yükümlülükler çerçevesinde kentsel rantların vergilendirilmesi, Eskişehir Osmangazi 
Üniversitesi İBF Dergisi, 13(2), 77-100. https://doi.org/10.17153/oguiibf.339176

TEGOVA (t.y.). Setting standards for European valuers. https://www.tegova.org/

Toprak Koruma ve Arazi Kullanımı Kanununu, (2005). Yayımlandığ1 Düstur; Tertip: 5 Cilt: 14 Sayfa: 9515.Kanun Numaras1: 5403, T.C. Resmi Gazete (25880, 19/7/2005)

Uluslararası Değerleme Standartları (2017). Uluslararası Değerleme Standartları Konseyi (IVSC).

Vuuren, D. J. (2017). Modified sales comparison method: valuing under (un)certainty, Journal of
Property Investment \& Finance, 35(1), 101-110. https://doi.org/10.1108/JPIF-09-2016-0074

Vergi Usul Kanunu, (1961). Yayımlandığı Düstur; Tertip: 4 Cilt: 1 Sayfa: 1037.Kanun Numarası: 213, Kabul Tarihi: 4/1/1961, T.C. Resmi Gazete $(10703,10 / 1 / 1961)$

Yıldız, N. (2000). Kamulaştırma tekniği, Türk Mühendis Mimarlar Odaları Birliği, Harita ve Kadastro Mühendisleri Odası, Ankara.

Yomralığlu, T., Nişancı, R., Çete, M. \& Candaş, E. (2011). Dünya'da arazi yönetimi, Türkiye'de Sürdürülebilir Arazi Yönetimi Çalıştayı, 26-27 Mayıs 2011, Okan Üniversitesi, İstanbul. 